\title{
Cloning and Expression of the Cutinase A Gene of Botrytis cinerea
}

\author{
C. J. B. van der Vlugt-Bergmans, C. A. M. Wagemakers, J. A. L. van Kan \\ Department of Phytopathology, Wageningen Agricultural University, P.O. Box 8025, 6700 EE Wageningen, \\ The Netherlands \\ Received 11 March 1996. Accepted 3 November 1996.
}

\begin{abstract}
Cutinase of Botrytis cinerea has been suggested to play an important role in penetration of host tissues. A protein fraction with cutin hydrolyzing activity was purified from culture filtrates of $B$. cinerea induced for cutinase activity. An 18-kDa protein in this fraction was identified as cutinase and the corresponding gene $c u t A$ was cloned. The gene is present in a single copy in the genome of $B$. cinerea strain SAS56 and its predicted amino acid sequence shows significant homology ( 31 to $35 \%$ identity) to other fungal cutinases. RNA blot analysis showed that cutA mRNA is induced in vitro by the cutin monomer 16-hydroxyhexadecanoic acid and repressed by glucose. The expression of cutA during infection of tomato leaves is low during early phases of infection, but high when the fungus has colonized the leaf and starts to sporulate.
\end{abstract}

Additional keywords: grey mold, pathogenicity gene.

The cuticle of aerial plant parts is the first barrier a plant pathogenic fungus must breach for direct penetration of the epidermis. The structural component of the cuticle is cutin, a polymer composed of mainly $\mathrm{C} 16$ and $\mathrm{C} 18$ hydroxy fatty acids, which are predominantly linked by ester bonds (Martin and Juniper 1970). The enzyme cutinase releases fatty acids from cutin by hydrolysis of the ester bonds. Production of cutinase during growth on cutin in vitro has been reported for over 20 plant pathogenic fungi (Baker and Bateman 1978; Ettinger et al. 1987; Trail and Köller 1990).

Botrytis cinerea Pers.:Fr., a ubiquitous plant pathogen with a very wide host range (Jarvis 1977), is able to infect its host by direct penetration of the cuticle. Evidence for enzymemediated penetration has come from electron microscopy studies (McKeen 1974; Rijkenberg et al. 1980). A role for cutinase was proposed because lesion formation by $B$. cinerea was reduced by $80 \%$ on gerbera flowers treated with antibodies raised against cutinase (Salinas 1992). Cutinase activity in B. cinerea was first demonstrated by Shishiyama et al. (1970) and Baker and Bateman (1978). Production is induced by

Corresponding author: J. A. L. van Kan;

E-mail jan.vankan@medew.fyto.wau.nl

Present address C. J. B. van der Vlugt-Bergmans: Wageningen Agricultural University, Department of Food Science, Division of Industrial Microbiology, P. O. Box 8129, 6700 EV Wageningen, The Netherlands.

The nucleotide sequence data are in the EMBL and GenBank databases under accession number Z69264. cutin, cutin hydrolysate, and cutin monomers such as 16hydroxyhexadecanoic acid (16-hha), and it is repressed by glucose (Salinas et al. 1986; Salinas 1992). The enzyme has been purified from $B$. cinerea strain $\mathrm{Bc} 7$ and identified as an 18-kDa protein (Salinas 1992). Inhibition of enzyme activity by diisopropylfluorophosphate indicated the involvement of a serine residue in the active center of the enzyme. Cutinases, including the one of $B$. cinerea, belong to the class of serine esterases that contain the catalytic triad (serine, histidine, and aspartate), with the active serine in the consensus sequence Gly-His/Tyr-Ser-X-Gly (Martinez et al. 1992). This group of enzymes hydrolyzes the model substrate $p$-nitrophenyl butyrate (PNB; Purdy and Kolattukudy 1973), which is widely used in the purification of cutinase. However, to demonstrate specific cutin hydrolysis, the enzyme should be tested on cutin, for which mostly radioactively labeled cutin is used (Purdy and Kolattukudy 1973, 1975).

The present work was undertaken to determine whether $B$. cinerea requires cutinase for successful penetration. Here we report the partial purification of cutinase A and the cloning and expression analysis of the corresponding cutA gene. In the accompanying paper (van Kan et al. 1997) we describe the analysis of cutA gene expression using reporter gene fusions and the construction of cutinase A-deficient mutants by gene disruption.

\section{RESULTS}

Purification of PNB hydrolytic enzymes.

In $B$. cinerea cutinase production is induced by cutin or monomers of cutin such as 16-hha (Salinas 1992). Enzyme activity can be determined using radioactively labeled cutin or PNB as a substrate (Purdy and Kolattukudy 1973, 1975). In this study, PNB was used to assay esterase activity in fractions obtained during the purification process. However, esterases other than cutinase can also hydrolyze this substrate and might be co-purified. Therefore, (partially) purified fractions are referred to as PNB hydrolytic activities.

$B$. cinerea was grown in liquid culture in the presence of 16-hha. The culture filtrate was concentrated and proteins were fractionated by gel filtration. PNB hydrolytic activity was detected in fractions 42 to 48 (peak I) and 56 to 64 (peak II) of the eluent (Fig. 1). Pooled fractions of each peak were separately subjected to chromatofocusing and the resulting fractions were tested. PNB hydrolytic activity from peak I eluted at pH 7.0 (Fig. 1, fractions 20 to 22, peak IA) and the 

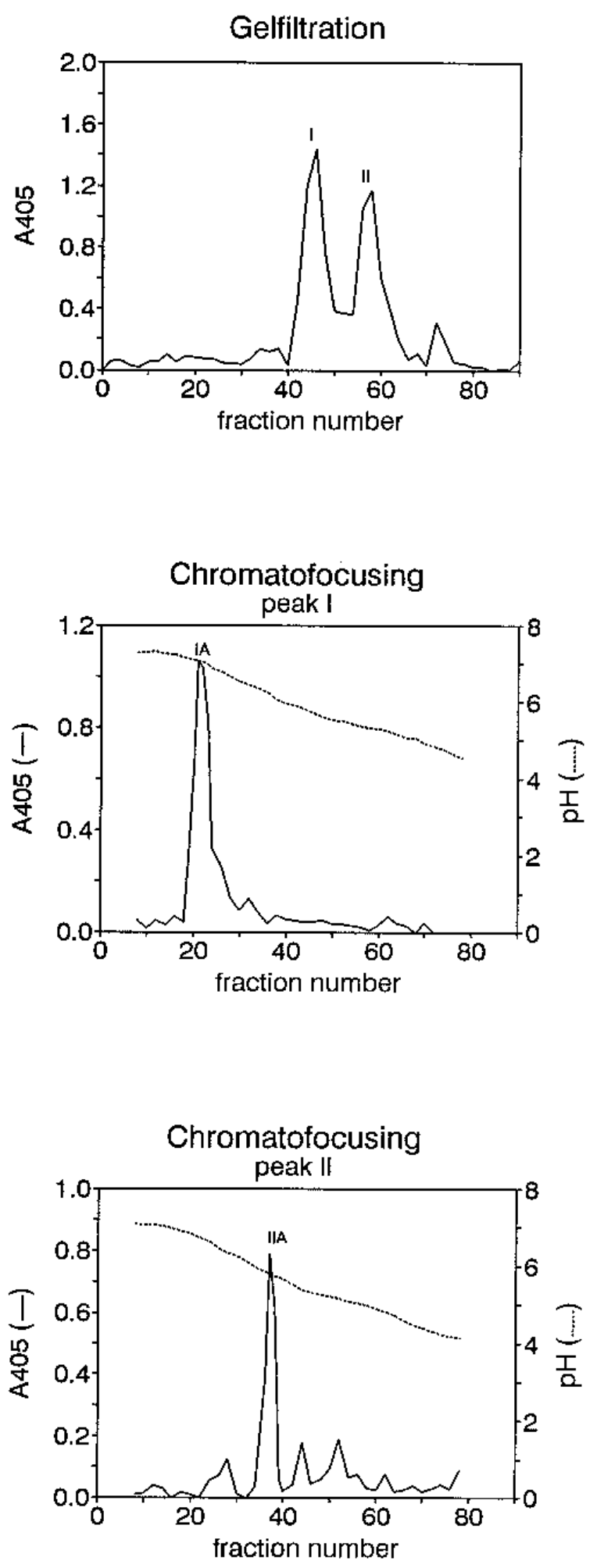

Fig. 1. Profiles of PNB hydrolytic activity in fractions obtained after gel filtration and chromatofocusing. PNB hydrolysis was measured in even fractions eluted from the Sephadex G-50 column. Two peaks I (fractions 42 to 48 ) and II (fractions 56 to 64) showed significant activity. Both peaks were subjected to chromatofocusing. In even fractions PNB hydrolytic activity and $\mathrm{pH}$ were measured. Peak IA (fractions 20 to 22) and peak IIA (fractions 36 to 38 ) contained highest PNB hydrolytic activity. activity from peak II eluted at pH 5.8 (fractions 36 to 38, peak IIA). This indicates the presence of two different PNB hydrolyzing enzymes. The protein composition of peaks IA and IIA was analyzed by SDS-PAGE. Peak IA contained two proteins of about 80 and $11 \mathrm{kDa}$, while peak IIA contained two proteins of 45 and $18 \mathrm{kDa}$ (Fig. 2). Further purification was hampered by the limiting amount of protein in the two fractions ( $<50 \mu \mathrm{g}$ each from 2-liter culture filtrate). Therefore it was decided to characterize the cutin hydrolyzing activity and to analyze the fractions by protein sequencing.

\section{Characterization of purified proteins.}

Determination of cutinase activity. Crude filtrates of B. cinerea cultures, induced with 16-hha, and the enzyme preparations of peaks IA and IIA were incubated with cutin labeled with the chromogenic group Remazol Brilliant Blue R (RBB, Wolf and Wirth 1990). Cutin-RBB hydrolytic activity could not be detected in crude culture filtrates. The fraction from peak IIA released a blue colored product from the insoluble substrate into solution, whereas the fraction from peak IA did not. The release was dependent on the presence of detergent ( $0.5 \%$ Triton). The activity in peak IIA was abolished by boiling. The optimal $\mathrm{pH}$ for cutin-RBB hydrolysis was 5.6, in agreement with the optimal $\mathrm{pH}$ reported for hydrolysis of radioactive cutin by cutinase from B. cinerea strain Bc7 (Salinas et al. 1986).

Cutin-RBB hydrolytic activity could be quantified by measuring the increase in the absorption at $590 \mathrm{~nm}$ caused by the release of RBB-labeled material into the solution from the insoluble substrate. From peaks IA and IIA, equal amounts of

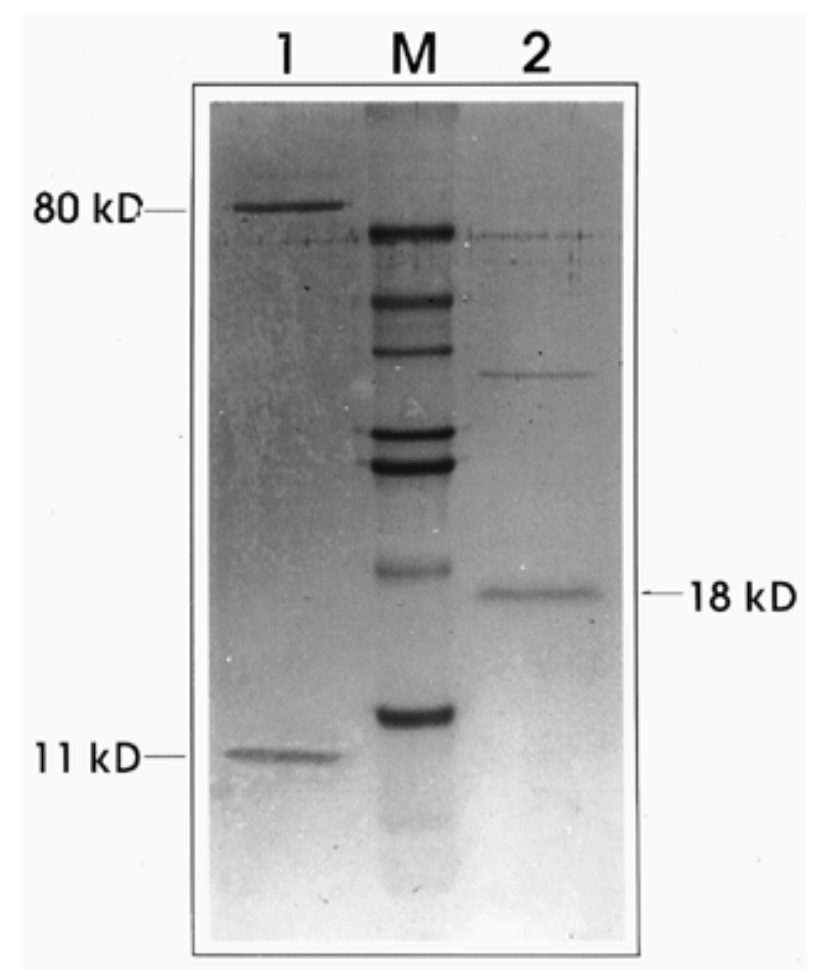

Fig. 2. SDS-polyacrylamide gel electrophoresis of peak IA (lane 1) and peak IIA (lane 2). Lane M contains marker proteins with molecular weights of $66,45,36,29,24,20$ and $14.2 \mathrm{kDa}$. Proteins were stained with Coomassie Brilliant blue R-250. 
PNB hydrolyzing activity were incubated with cutin-RBB. In peak IIA a $\triangle \mathrm{A} 590$ of $0.566 / \mathrm{h}$ was measured, whereas in peak IA a $\Delta$ A590 of only $0.057 / \mathrm{h}$ was measured. The hydrolysis products released by peak IIA could be extracted from the aqueous phase with chloroform, but the quantity of hydrolysis products released from the substrate was insufficient for chemical identification.

These results indicate that peak IIA but not peak IA contains cutinase activity. Since a cutinase purified from $B$. cinerea strain $\mathrm{Bc} 7$ was identified as an $18-\mathrm{kDa}$ protein (Salinas 1992 ), the $18-\mathrm{kDa}$ protein in peak IIA was assumed to be cutinase. This protein was subjected to amino acid sequence analysis for further identification and the design of gene specific primers for PCR based gene cloning. From the fraction representing peak IA, the 80 - and $11-\mathrm{kDa}$ proteins were subjected to N-terminal sequence analysis.

Amino acid sequence analysis. The $\mathrm{N}$-terminus and four internal sequences $(\mathrm{p} 7, \mathrm{p} 8, \mathrm{p} 9$ and $\mathrm{p} 11)$ of the $18-\mathrm{kDa}$ protein were determined (Table 1). The N-terminal sequence showed significant identity (50 to $60 \%$ over 17 amino acids) to sequences in the $\mathrm{N}$-terminal region of cutinases of Colletotrichum gloeosporioides, C. capsici, Alternaria brassicicola, Magnaporthe grisea, Ascochyta rabiei, and Fusarium solani (see below). Peptides p7, p8 and p11 also aligned with these cutinases, whereas peptide $\mathrm{p} 9$ could not be aligned. Peptide p8 contains a serine residue in the motif. G-H/Y-S-X$\mathrm{G}$, which is characteristic of the active center of serine esterases (Martinez et al. 1992). Based on the sequence similarities to fungal cutinases, the presence of the active site residue serine and its cutin-RBB hydrolyzing activity, the $18-\mathrm{kDa}$ protein was designated cutinase $\mathrm{A}$.

$\mathrm{N}$-terminal sequences of the $11-$ and $80-\mathrm{kDa}$ proteins from peak IA were determined (Table 1). The N-terminus of the 80$\mathrm{kDa}$ protein showed homology (10 out of 16 amino acids identical) to glucoamylase of Neurospora crassa (Stone et al. 1993). The N-terminal sequence of the 11-kDa protein showed no homology to sequences in the SWISS-PROT database. PCR primers were designed and the corresponding gene, designated $e k d A$, was cloned and sequenced (not shown). The sequence of the $e k d \mathrm{~A}$ gene indicated that the purified $11-\mathrm{kDa}$ protein is a degradation product of an intracellular protein of 144 amino acids, probably released from disintegrating mycelium (results not shown). This gene was not studied further.

\section{Isolation and characterization of the cutA gene.}

Amino acid sequences of cutinase A were used to design oligonucleotide primers for RT-PCR to amplify coding regions of the corresponding gene, designated cutA. Primer combinations $\mathrm{N}+11$ and $\mathrm{N}+8$ (Table 1) amplified fragments of 300 and $380 \mathrm{bp}$, respectively. After cloning and sequence analysis of the 380-bp fragment, an open reading frame (ORF) of 120 amino acids was deduced, including peptide sequences of the $\mathrm{N}$-terminus, p7, p8, and p11. Using the cloned PCR fragment as a probe, a genomic library of $B$. cinerea was screened to isolate the entire $\operatorname{cut} \mathrm{A}$ gene. Five recombinant phages were isolated, in which the cutA gene was mapped on two SalI fragments in each phage, one of $5.0 \mathrm{~kb}$ and a second fragment of variable size. This is in agreement with the presence of a SalI site in the probe. Two SalI fragments of 2.5 and $5.0 \mathrm{~kb}$ were subcloned, a restriction map of the cutA locus was made and the sequence determined (Fig. 3A and B). The complete sequence represented in plasmid pCut1 (Fig. 3C) is shown in Figure 4. This sequence was aligned with the cDNA sequence of the PCR fragment (Fig. 3D) to identify the coding region and confirm the position of two introns of 78 and $66 \mathrm{nt}$, respectively.

Upstream of the coding sequence $1.4 \mathrm{~kb}$ of the promoter region was sequenced (Fig. 4). No typical CAAT and TATA boxes for transcription initiation could be identified. At the 3'end of the coding sequence $0.7 \mathrm{~kb}$ of the terminator was sequenced. A polyadenylation signal consensus sequence (AATAAA) is not present.

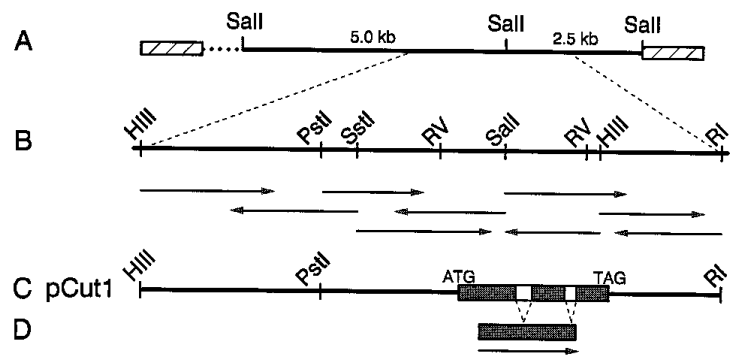

Fig. 3. Analysis of the Botrytis cinerea cutA gene. A, Map of recombinant phage containing $5.0-$ and $2.5-\mathrm{kb}$ SalI fragments hybridizing to cutA probe. B, Partial restriction map and sequencing strategy of cutA. C, Organization of the $c u t A$ gene. The complete sequence cloned in plasmid pCut1 is presented in Figure 4. D, Position of cDNA fragment amplified by primers $\mathrm{N}$ and 11 (Table 1). Abbreviations of restriction enzymes include: $\mathrm{RI}=E c o \mathrm{RI}, \mathrm{RV}=E c o \mathrm{RV}$, HIII $=$ HindIII. Discontinuous lines (A) represent DNA region of unknown length. Hatched bars represent phage arms. Arrows indicate direction and extent of sequencing. Closed bars represent coding sequences, open bars represent introns. Start and stop codons are shown.

Table 1: Sequences of N-termini of 18-, 11-, and 80-kDa proteins and peptides obtained after tryptic digests of the 18-kDa proteins ${ }^{\mathrm{a}}$

\begin{tabular}{|c|c|c|c|}
\hline Peptide & Amino acid sequence & Primer & Nucleotide sequence \\
\hline \multicolumn{4}{|c|}{ I } \\
\hline $18 \mathrm{kDa} \mathrm{N}$-terminus & AXSDVTVIFARGXSEXG & $\mathrm{N}$ & 5'-GAYGTIAYIGTIATHTTYGC-3' \\
\hline $\mathrm{p} 7$ & LLPAETTAK & & \\
\hline p8 & LVISGYSQGGQLVHNAAK & 8 & 5'-CCNGTYRTICAIGTRTTRCG-3' \\
\hline p9 & TYGMDTTAAAAFVK & & \\
\hline p 11 & ISXAVIFGDPDNGDPV & 11 & 5'-GGRTCICCRTTRTCIGGRTCNCC-3' \\
\hline $11 \mathrm{kDa}$ N-terminus & AXGITVTNKST & & \\
\hline $80 \mathrm{kDa}$ N-terminus & XVDSFIAXEXPIAFRNL & & \\
\hline
\end{tabular}

${ }^{a}$ Underlined amino acid sequences refer to those used for PCR primer design. X refers to an unidentified amino acid residue. In the sequence of the 18 $\mathrm{kDa} \mathrm{N}$ terminus, an ambiguity (I or T) occurred at the 6th position. In the nucleotide sequences of the primers, the following code is used: $\mathrm{N}=\mathrm{A}, \mathrm{C}$, $\mathrm{G}$ or $\mathrm{T} ; \mathrm{Y}=\mathrm{C}$ or $\mathrm{T} ; \mathrm{R}=\mathrm{A}$ or $\mathrm{G} ; \mathrm{H}=\mathrm{A}, \mathrm{C}$ or $\mathrm{T} ; \mathrm{I}=$ inosine. Primers 8 and 11 are complementary to the coding sequences 
1501

1561

1621

1681

1741

1801

1861

1921

1981

2041

2101

2161

2221

2281

2341

2401

2461

2521

2581

2641

2701

2761

2821 aagctttctcaatatggggtagccttatgtcccttcccttgtccttgctgtcgatctcac cattttccatttctcttcacctcttcccctccgtgattcaaccacacctctagaatct ttaatgcctcggcagttgaagacatacacgggcctcgtcaattatcgcacattgtactac tcaccaacttaatgaatactggcatctaaacacggtattcaaaagatgcgagatgtaca gacagacactcgcaggtcatgacaaattccccgtcggacttccacattggaattttgaga gtccaagcaaaaagttacaatggtgttatgttgcatcacaatcaaatcttccttactt tttctccacacaggcaccaccatcctccttatgcttcttccatccttaacgtttcaaaa gtcggattcatctgaaaaagttacatcaaaagcaatttttcgtctcatactaattgatat attggcaaataatcaatgtcaagtcgaggtatccacttcaaaggtatcaaagcaccaa tatcccggctaccaacatgtttaagccccgccaaacataacaaadcggtctaagatct aggaaacgggaggtgatatgccaagtggagatcctttgtaccaatcgcatctcaagaatg tttttgcaactctgccataagcgccgagcatgtgctttgttcttctccccagatatatcg tattaacgtctattttccgtcatccctaaattgggattgtactgccggggaagtttccca agatgtcgattccaggtccgatgaataactattctggcatcgatgcgaggctagtgcagc tgcagttggttgaagtgcctgtccaagctagagccttaattattagcgcatagaggaaaa agctcggcttagaggtctagtgatcatacacagagtcgaacattcattgagataacagta ctgtaccccatattgaagggtaatcattgctaaattggttttcatgaggagctgtgtgga gctcaccaccgctatttctcctcggcacttctactttttaataatagaaacgttgttat aaccttcgtctggtgtgtgatagcatctaggactaagcccggtcggttgtcatctggtgt gttgaatacctcggtatttagcaagttcatcttgactggccgacaagcatctagatact attatcggcttgaaacttcatcccaaggcctccgaggaattaagcatatgttatgatctc acggtgttccccacaaaataaatgacgttcctggttgtcgggttcaactttgaagatat aagtcaagatgatttcctttcaacgcaatttctctcatcactgatcatcgtctatacat tctttcactgatatcttcactaatccttctattctcattcgactactcattattcattgt acaaatatcaatacatcaatt caaaATGAAGACCTCAGCTCAACAACTCTTGTCCGCT $M \quad K \quad T \quad S \quad A \quad Q \quad Q \quad I \quad L \quad S \quad A$ CTCCTCCTTCCTCTCTCCGTCTTAGCCGCTCCAACAGGTTCCATTGAAGCTAGAGCATGC

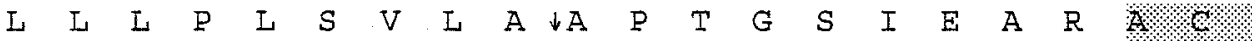
TCAGATGTGACGGTCATCTTTGCCCGTGGAACGACTGAGACTGGAACTCTCGGTACTGTA

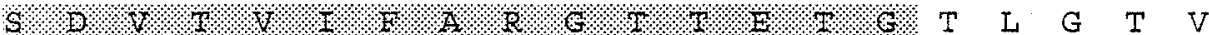
GTCGGACCACCCTTCCTCGCCGCTCTCAAATCTGCTCTTGGGTCATCTTCAGTCACCATG $\begin{array}{llllllllllllllllllll}V & G & P & P & F & L & A & A & L & K & S & A & L & G & S & S & S & V & T & M\end{array}$ AATGGTGTCGACTACCCAGCAGATGTTCCAGGATTTTTGCAAGGAGGCGATCCTGCTGGC

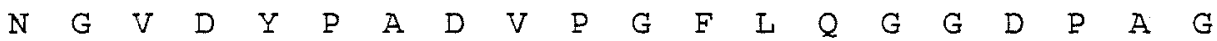
AGTCAGACTATgtatgtttcttttctgagattcagcgtgactagttgtttetcctct $S Q T$ M taaaacatttactcacatctcaatacagGGCCACAATGGTCACATCAACCTTATCCAGC A. $T$ M $\quad V \quad T \quad S \quad T \quad L \quad S \quad S$ TGCCCAGACACAAAACTCGTCATCTCTGGCTACTCCCAAGGTGGCCAACTCGTACATAAC

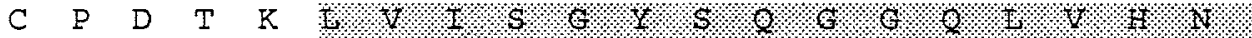
GCCGCCAAACTTTTACCAGCCGAAACAACAGCTAAAATCAGCTCTGCCGTTATCTTCGGT

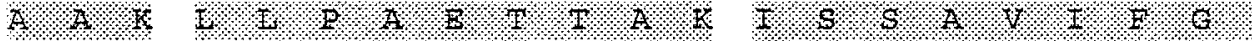
GACCCAGgttcgtcccaacccettacatattccacaatatggcatgaaatctgaaacta 019 acacaattaccagACAATGGAGATCCAGTCCAAGGTGTCTCAGCCGATAGAACAGATATC

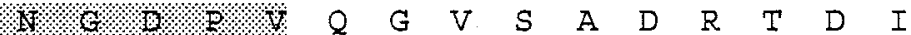
ATTTGTCACGCTGGAGATAACATCTGTCAAGGCGGAAGCTTGATCTTACTGGCTCATCTG

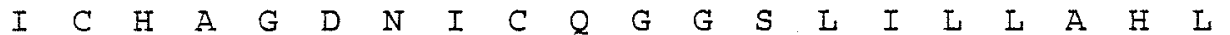
ACTTATGGAATGGATACGACGGCAGCAGCGGCATTTGTTAAGAAAGCAGCCGGATTGTAG

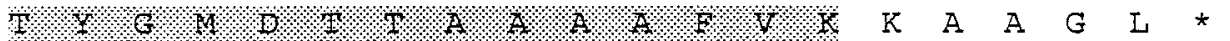
ggcggatgagtatccgcagtgcggattggattggatggagttacttggaatgatatgata cgacatgggcagccctcattctcgaaattgggcatggagttttacgtttctggcagta aaggctttctggtacattttacttctttctccctactggactttcctggctcttctt tcctgttaggcaaacagcacttcaattgggatgagctatctcgactgtagagattctcgt cagacggtattggattggctaggccagtagggggtttacttatatttcgcttccttgctt gcaggtcagcattttattttacacacatcaaatatcaaatatcaaaaggctggttcgag aatggtttataatctgaattgacattctctgcgaatccgtttatgacttgtgatttgagc tatcttcttggtggatcaatagaagagaaaagccgagatattgacttaattatctcat ttacatattggaataagtcacatacgaattacaaaagatataaggagatgctagttttgc agggtttgaagtattaagttagatatagcttaccctcctagtagttgaacctgtatacgt gattaagagtagcagtcgcaagaattc

Fig. 4. Nucleotide sequence of the Botrytis cinerea cutA gene. The sequence starts at a HindIII site and extends to an EcoRI site as shown in Figure 3B. The deduced amino acid sequence is shown below the open reading frame. Sequences of the N-terminus and peptides p8, p7, p11, and p9, respectively, as determined by protein sequencing, are indicated by shaded boxes. The arrow indicates the predicted cleavage site of the signal sequence. The nucleotide sequence data are in the EMBL and GenBank databases under accession number Z69264. 
The ORF in the cutA gene predicts a protein of 202 amino acids. The predicted cleavage site of the signal sequence, according to the $(-3,-1)$ rule (Von Heijne 1986), is between positions 20 and 21 (arrow in Fig. 4), whereas the N-terminal sequence of the purified protein starts at position 30. This indicates that additional $\mathrm{N}$-terminal processing steps occur during or after secretion in the culture medium. One discrepancy was found between the $\mathrm{N}$-terminal sequence determined on the purified protein and the ORF predicted from the DNA sequence ( $S$ versus $T$, respectively in position 14). All internal peptide sequences obtained from protein sequencing (shaded in Fig. 4) fully match the deduced sequence.

A computer alignment of the $B$. cinerea cutinase A with other fungal cutinases is shown in Figure 5. Similarity between the cutinase of $B$. cinerea and other cloned cutinases varies from 50 to $53 \%$. The amino acid identity, as shown by dots in Figure 5, is 31 to $35 \%$. These scores are rather low in comparison to a similarity of 64 to $74 \%$ and identity of 48 to $64 \%$ among cutinases of $F$. solani, A. rabiei, C. capsici, and A. brassicicola. The functional serine residue is present in a highly conserved region (GYSGG, positions 115 to 119 in the B. cinerea protein) in all sequences. Residues D169 and H182, forming the catalytic triad together with $\mathrm{S} 117$, are conserved at similar positions in the $B$. cinerea cutinase $\mathrm{A}$ as compared to other cutinases.

The copy number of the cutA gene was determined by Southern blot analysis of genomic DNA of B.cinerea strain SAS56 restricted with several enzymes (Fig. 6). A probe containing part of the cutinase encoding sequence hybridized to single fragments in the EcoRI, EcoRV, and HindIII digests. The SalI digest shows two hybridization signals due to the presence of a SalI site in the coding region. A second, weakly hybridizing fragment in the PstI digest was not predicted from the restriction map and was not reproducible. It is concluded that cutA occurs as a single copy gene in the genome of $B$. cinerea strain SAS56.

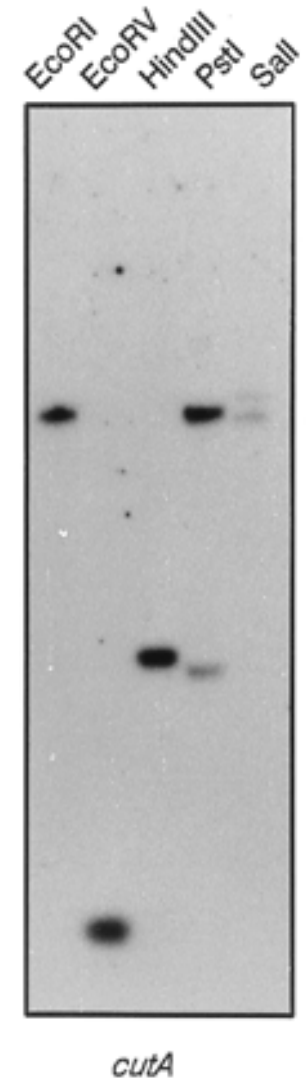

Fig. 6. Autoradiograph of Southern blot containing genomic DNA of Botrytis cinerea strain SAS56 digested with restriction enzymes as indicated. Molecular size markers are indicated in $\mathrm{kb}$. The blot was hybridized with the cloned cutA PCR fragment.

\section{$\mathrm{N}$}

\begin{tabular}{|c|c|c|c|c|c|c|c|c|}
\hline C & -- & $-\cdots--\cdots-M$ & KTSAQQLLSA & LLLPLSVI_AA & PTGSIEARHO & BDUTY FRG & T.FTGTLGTV & VGPPFLAALK \\
\hline 9 & MKFLSVLSLA & ITLAA-AAPV & EV--ETGVA- & . ETRQ . STRN & ELETGSSS. & PK. IY....A & S..P.NM.IS & A. IVAD..E \\
\hline $\mathrm{C}$ & MKFLSI ISLA & VSLVA-AAPV & VGLDTGVAN & . EARQ.STRN & ELE. GSSSN. & PK.IY ....A & S. P.NM.IS & A. IVAD. . E \\
\hline & & & MMINLN . . LS & KPCQA.TTRN & ELETGSSD. . & PRTIF. & S. A. NM.AL & FTAN . . E \\
\hline & MQFITVALTL & IALAL-ASPI & NVEKPSEL & EARQ.NSVRS & DLI.GN.A. & PS.IL. & SG.V.NM.LS & A. TNVASR.E \\
\hline & - -MKFFAFS & MLIG & LALRRTTLE & VRQLDPIIRS & ELEQGSSSS. & PKAIL. & S. I. NM.VS & A. AVAS. \\
\hline & ---MKFFALT & TLLt & . NPAQELE & ARQLGRTTRD & DLINGNSAS. & R. . IF & S...N. $-\mathrm{T}$ & L. . SIASN.E \\
\hline & & & & & & & & 21 \\
\hline & SALGS & NGVD--YPAD & -FLQG & GDPAGSQTMA & TMVTSTLSSC & PDTKMU - SGY & $S \odot G \& O I$ & AXOS. P A ETW \\
\hline & RIY. ANN . WV & Q..G & F-LPD. & TSS. AINEAR & RLF . LANTK. & . NAAI.SG.. & ...TAV & ISG.STTIKN \\
\hline & RY.A.Q.WV & Q . . GGP.S & E. & TSRVAINEAK & RLF. LANTK. & .NSAV.AG. . & $\ldots$ TAV & ISE.SSTIQN \\
\hline & . Y.A.N.WV & Q..GGP.T.G & A. & TSQ . AIREAQ & RLFNLAASK. & .N.PITAG. . & $\ldots A$ & . S.AVQD \\
\hline & REF - RNDIWV & Q..GDP.D.A & $S P$ & TTQGA & R. F. LANTK. & . NAAV . AG. & $\ldots \mathrm{TF}$ & VSEM . . AVQD \\
\hline & - . Y.ADQIWV & Q. .GGP.T. & L.S & TSQSAINEAV & RLFNEANTK. & .S.PI.AG. & TAVN & IPK. - DAVR. \\
\hline & . F. KDG.WI & Q..GGA.R.T & I $\mathrm{C}$ & TSS & $\mathrm{TK}$ & T. IA & $S$ & DSAIRD \\
\hline \multicolumn{4}{|c|}{ P11 } & * & . & P9 & & \\
\hline & MSSI & - & $2 G V$ & ICHAGDNICQ & GGSLILLAHL & HGMVT/ $/ \mathrm{X}$ & $\mathrm{A}, \mathrm{HXK}$ & --202 \\
\hline & Q.KGV & LGRI & K.EV & Y.DIA.AV.Y & . TLF . P. . F & L.QT.AAV. & PR. LQARI . * & $\ldots \ldots 224$ \\
\hline & Q.KGV.LSAI & LGR I & TSK.EV & Y.ALA.AV . Y & .TLF . P.F & L. QA. AATS. & PR . LAARI . * & $-\ldots \ldots 228$ \\
\hline & Q.KGV. L & . GRI & PNE & Y.ET. . LV.N & . TLI. TP. & L. SDEAAVQ. & PT. LRAQIDS & $A * \ldots-\ldots 9$ \\
\hline & Q.KGV & RGRI & K.EV & Y.N.S.AV.F & . TLFL . P . F & L. TTESSI. & PNWLIRQIRA & $A * \ldots 228$ \\
\hline & RVVGT.L. . Y & NKGI & & Y.EV . LV.D & .TLI.TVS.F & L. LEEAAGP. & PE.L.SKI.A & --223 \\
\hline & .AGT.L..Y & TKNLQ. RGR I & TYPA & F.NT. . LV.T & SITVAAP & A. P. ARGP. & PE. LIEKVRA & VRGSA * 230 \\
\hline
\end{tabular}

Fig. 5. Comparison of cutinase sequences from Botrytis cinerea, Colletotrichum gloeosporioides (Ettinger et al. 1987), C. capsici (Ettinger et al. 1987), Alternaria brassicicola (Yao and Köller 1994), Magnaporthe grisea (Sweigard et al. 1992) Ascochyta rabiei (R. Tenhaken, unpublished, accession number in GenEMBL: X65628) and Fusarium solani f. sp. pisi (Soliday et al. 1989). Amino acids identical to cutinase of B. cinerea are indicated by dots. Gaps introduced for optimal alignment are indicated by a dash. Asterisks above the alignment indicate amino acids participating in catalytic triad (Martinez et al. 1992). Shaded boxes indicate the position of peptides determined by protein sequencing. 


\section{In vitro expression of the $\operatorname{cutA}$ gene.}

Gene expression of cutA was analyzed in cultures of $B$. cinerea grown under different conditions and compared to PNB hydrolytic activity. A start culture of $B$. cinerea was diluted (day 0) in media A (16-hha + glucose), B (16-hha), or C (glucose) and sampled during each of the following 5 to 8 days. Glucose measurements showed that glucose was already depleted from culture medium A and $\mathrm{C}$ at day 2 . In the absence of glucose less fungal biomass developed (Fig. 7A, culture B).

\section{A}

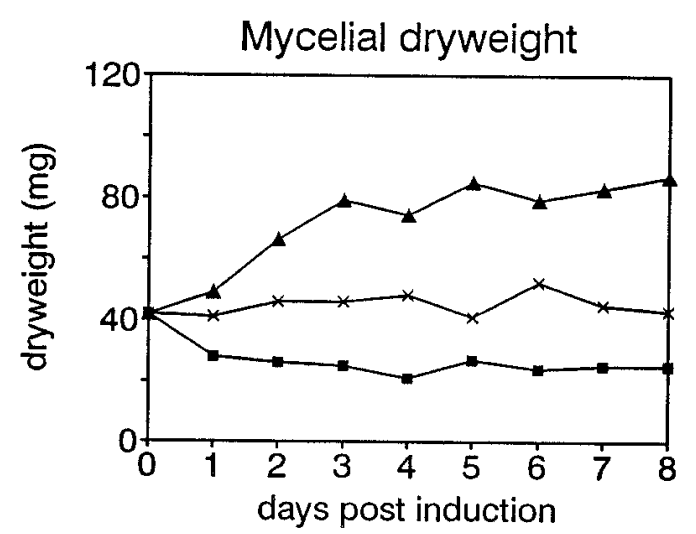

B
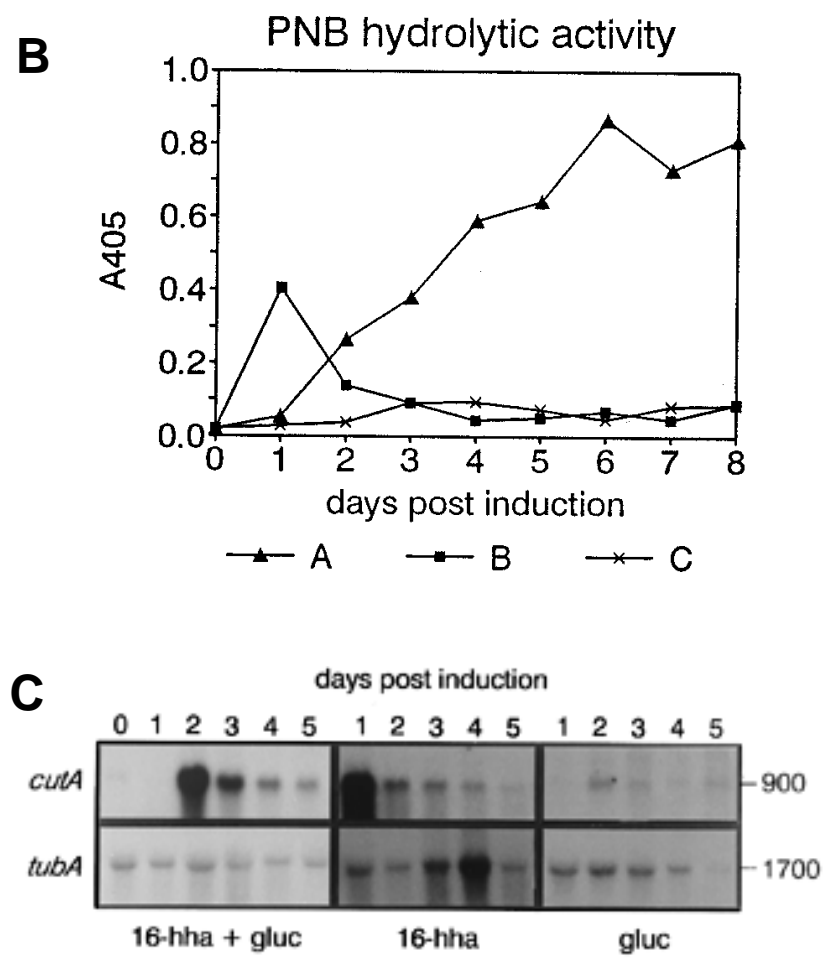

Fig. 7. Mycelial dry weight (A), PNB hydrolytic activity in culture filtrate (B) and RNA blot analysis of cutA expression (C) in cultures of Botrytis cinerea, grown under different conditions. A start culture of $B$. cinerea was diluted at day 0 in media A (16-hha + glucose), B (16-hha) or $\mathrm{C}$ (glucose) and sampled during each of the following days. Mycelial dry weights were determined in samples of 50-ml culture medium. RNA blots of total RNA were hybridized with probes derived from the cutA and the $B$. cinerea $\beta$-tubulin gene (tubA). Sizes of mRNAs (in nt) are shown in the right margin. All autoradiographs are overnight exposures.
Production of PNB hydrolytic activities in the start and subcultures sampled during 8 days postinduction (d.p.i.) and RNA blot analysis of RNA isolated from the start culture at day 0 and from cultures $\mathrm{A}, \mathrm{B}$, and $\mathrm{C}$ during 1 to 5 d.p.i., is shown in Figure 7. The blots were hybridized with cutA and the constitutively expressed $\beta$-tubulin gene of $B$. cinerea (tubA, accession number Z69263 in GenEMBL) to standardize mRNA levels. A single cutA transcript of 900 nt was detected, in agreement with the DNA sequence data.

In medium A, PNB hydrolytic activity (Fig. 7B) was first detected at 2 d.p.i. reaching a maximum activity at 6 d.p.i. When glucose was depleted from the medium at 2 d.p.i., the cutA mRNA (Fig. 7C) was strongly expressed and then decreased from 3 d.p.i. onwards. The continuous increase in PNB hydrolytic activity in medium A is probably caused by esterases other than cutinase (e.g. fraction IA, Figs. 1 and 2).

In medium $\mathrm{B}$, in the absence of glucose, the cutA mRNA (Fig. 7C) was expressed at a high level at 1 d.p.i., indicating that glucose repressed the cutA gene at day 1 in medium A. Both in media $\mathrm{A}$ and $\mathrm{B}$ the cutA mRNA displays the same transient induction pattern (Fig. 7C). A transient peak activity in PNB hydrolysis was found at day 1 in medium B (Fig. 7B), presumably resulting mainly from the production of cutinase A. In the absence of the cutin monomer (medium C), no PNB hydrolytic activity was measured and only a very low hybridization signal of cutA mRNA was detected.

\section{In planta expression of the cutA gene.}

To analyze whether cutA is expressed during infection of host tissue, tomato leaves were inoculated with conidia of $B$. cinerea. Standard inoculation for successful and synchronized infection was performed with conidia resuspended in a buffer containing glucose and phosphate (Van den Heuvel 1981; Edlich et al. 1989). The first visible symptoms on inoculated tomato leaves were small water-soaked lesions at $16 \mathrm{~h}$ postinoculation (h.p.i.). These lesions became necrotic at 20 h.p.i. and their size remained unchanged until 72 h.p.i.. No new lesions appeared during that time, indicating that the primary infection occurred very synchronized. After 72 h.p.i., a subset of lesions developed into spreading lesions. At 120 h.p.i., the fungus had grown abundantly and started to sporulate from the expanded, necrotic lesions. Based on these symptom developments leaves were harvested for RNA isolation at 4, 8, 12, 16, and 20 h.p.i., when penetration of host tissue occurs and the expression of cutA mRNA might be expected. Sampling continued until 120 h.p.i. to cover the whole infection process. RNA blot analysis of total RNA isolated from infected tomato leaves is shown in Figure 8. The blot was also hybridized with the tubA gene of $B$. cinerea to demonstrate the ability to detect fungal mRNAs in the total population of plant and fungal RNAs. This probe hybridized specifically with the fungal $\beta$ tubulin mRNA under the stringent conditions used. Under less stringent hybridization conditions a plant $\beta$-tubulin mRNA of smaller size was detected (results not shown). The cutA mRNA was first detectable at 12 h.p.i., stayed at a similar level as the $t u b A$ mRNA and strongly increased at 120 h.p.i., when also the fungal biomass had increased.

\section{DISCUSSION}

Two fractions containing PNB hydrolytic activity were purified from a liquid culture of $B$. cinerea grown in the pres- 
ence of the cutin monomer 16-hha. PNB is not a specific substrate for cutinase and is also hydrolyzed by other esterases. Therefore, cutin labeled with Remazol Brilliant Blue R (RBB, Wolf and Wirth 1990) was used to measure cutin hydrolysis in these fractions. Cutin-RBB hydrolytic activity was only present in the fraction containing an $18-\mathrm{kDa}$ protein, later identified as cutinase A, and not in the other PNB hydrolytic fraction containing $11-$ and $80-\mathrm{kDa}$ proteins. This is the first time that the use of cutin-RBB as a substrate for cutinase is reported. The method was not useful for assays on crude culture filtrates, probably because of interference by components of the medium or fungal exudates. On partially purified preparations, however, it proved to be a good alternative to radioactively labeled cutin. The radioactive labeling of cutin requires incorporation of $\left[{ }^{14} \mathrm{C}\right]$-fatty acids in vivo or treatment with high dosages of $\left[{ }^{3} \mathrm{H}\right]$ (Purdy and Kolattukudy 1973, 1975; Salinas et al. 1986). Both methods yield substantial radioactive waste during the processing of the labeled product. In contrast, purified cutin can be labeled with RBB and the resulting product only needs a few washing steps before use in enzyme assays. Furthermore, assays with radioactive cutin may require long incubation times, up to $18 \mathrm{~h}$ (Salinas et al. 1986). In the cutin-RBB assay, a significant absorption increase was obtained after $1 \mathrm{~h}$ of incubation. Unfortunately, we were not able to confirm that the hydrolysis products released from cutin-RBB are indeed RBB-labeled fatty acids.

The $18-\mathrm{kDa}$ protein was identified as cutinase $\mathrm{A}$, based on size, cutin-RBB hydrolytic activity and sequence similarity to previously cloned fungal cutinases. The catalytic triad comprising the amino acids serine, aspartic acid, and histidine was conserved. The cutA gene, present in a single copy in the genome of B. cinerea strain SAS56, encodes an ORF of 202 amino acids, of which $29 \mathrm{~N}$-terminal amino acids are removed during posttranslational processing to release a mature protein of 183 amino acids.

Gene expression of $c u t A$ and PNB hydrolysis in culture filtrate were analyzed in different $B$. cinerea cultures. The cutA gene is repressed by glucose (compare Fig. 7, media A and B) and requires the presence of an inducer (compare Fig. 7, media $\mathrm{A}$ and $\mathrm{C}$ ). PNB hydrolytic activity in media $\mathrm{B}$ and $\mathrm{C}$ correlated with cutA expression. In medium A, however, PNB hydrolysis increased until 6 d.p.i., whereas cutA expression was highest at 1 d.p.i. A correlation between cutA mRNA levels and cutinase activity in filtrates of cultures A, B, and C could not be investigated with the cutin-RBB substrate, as discussed above.

Expression of cutA during infection of tomato leaves by $B$. cinerea was first observed at 12 h.p.i., just before lesions ap- pear at 16 h.p.i. cutA expression was not strongly induced compared to the expression of the constitutively expressed tubA gene. The strong cutA expression observed at 120 h.p.i. might reflect cutin degradation during saprophytic growth of the fungus in the final stages of plant colonization. In the inoculation method used, the analysis of a role for cutinase in penetration of host tissue by $B$. cinerea is difficult. To achieve efficient and synchronous infection, leaves were inoculated by spraying conidial inoculum droplets containing glucose (Edlich et al. 1989; Van den Heuvel 1981), which was found to repress cutA expression (Fig. 7). The inoculation of tomato leaves with dry conidia results in inefficient and highly unsynchronized infection, making it inappropriate to investigate fungal gene expression over time by RNA blot analysis. The accompanying paper (van Kan et al. 1997) reports on the use of the reporter gene uidA encoding $\beta$-glucuronidase (Jefferson et al. 1987) to study cutinase A expression at early timepoints during infection in single germinating conidia. Cutinase A-deficient mutants, obtained by gene disruption, were used to evaluate the requirement of this gene for penetration of host tissue by $B$. cinerea.

\section{MATERIALS AND METHODS}

\section{Fungal growth.}

B. cinerea strain SAS56 (Van der Vlugt-Bergmans et al. 1993) was grown on malt extract agar (Oxoid, Basingstoke, England) or tPDA (potato dextrose agar containing $300 \mathrm{~g}$ of homogenized tomato leaves per liter) at $18^{\circ} \mathrm{C}$ in the dark. After 3-day cultures were exposed for $16 \mathrm{~h}$ to near-UV light. One week later conidia were collected from sporulating cultures and inoculated in Gamborg's B5 medium (Duchefa Biochemie BV, Haarlem, The Netherlands) supplemented with $0.3 \%$ (w/v) glucose (start culture) at a density of $10^{9}$ conidia per liter. After 4 days of growth in a rotary shaker at $160 \mathrm{rpm}, 20^{\circ} \mathrm{C}$, the cutin monomer 16-hydroxyhexadecanoic acid (16-hha, Sigma) was added as an inducer of cutinase expression at a final concentration of $0.05 \%(\mathrm{w} / \mathrm{v})$. Incubation was continued for 6 days.

For analyses of gene expression in vitro, a 2-day-old start culture was diluted fivefold in the following media: B5 medium $+0.3 \%$ glucose $+0.05 \%$ 16-hha $(\mathrm{A})$, B5 medium + $0.05 \%$ 16-hha (B), B5 medium $+0.3 \%$ glucose $(\mathrm{C})$. The remainder of the start culture ( $40 \%$ of the mycelium) was harvested. All three subcultures were incubated at $20^{\circ} \mathrm{C}, 160 \mathrm{rpm}$ and mycelium and culture filtrate were sampled during each of the following 8 days. The dry weight of the mycelium and PNB hydrolytic activity of the culture filtrates were determined.

The glucose concentration in liquid cultures was determined according to the method of Nelson (1944).

\section{hours post inoculation}

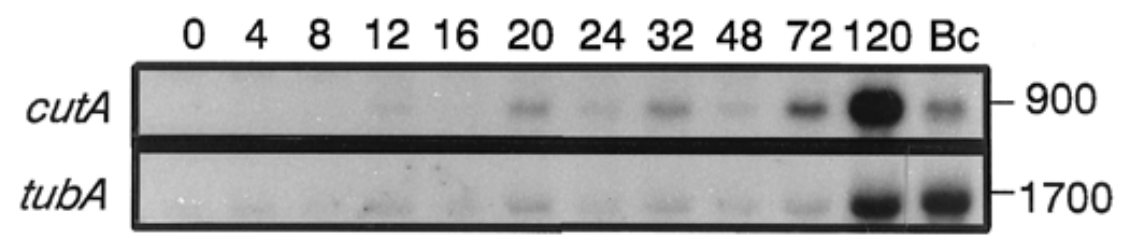

Fig. 8. Autoradiograph of RNA blot of total RNA isolated from infected tomato leaves at different time points (numbers refer to hours postinoculation) and from 1-day-old Botrytis cinerea mycelium grown in liquid medium $(\mathrm{Bc})$. The blot was hybridized with probes derived from the $c u t A$ and $t u b A$ genes of $B$. cinerea. Sizes of the mRNA (in nt) are shown in the right margin. 


\section{Enzyme assay for PNB hydrolytic activity.}

Culture filtrate or (partly) purified protein fractions were diluted in $25 \mathrm{mM}$ potassium phosphate buffer, $\mathrm{pH} 8.0$ and $0.05 \%(\mathrm{v} / \mathrm{v})$ Triton X-100 in a final volume of $450 \mu \mathrm{l}$. To this, $50 \mu \mathrm{l}$ of para-nitrophenyl butyrate (PNB, Sigma) resuspended at a concentration of $10 \mathrm{mM}$ in $0.25 \mathrm{mM}$ phosphate buffer, $\mathrm{pH}$ 7.0, and $0.5 \%(\mathrm{v} / \mathrm{v})$ Triton X-100 was added. After $1 \mathrm{~h}$ of incubation at $22^{\circ} \mathrm{C}$ PNB hydrolysis was measured spectrophotometrically at $405 \mathrm{~nm}$. Background caused by yellowish culture filtrate and/or nonenzymatic substrate degradation was determined in a parallel assay containing protein fraction that had been heated for $5 \mathrm{~min}$ at $100^{\circ} \mathrm{C}$, and subtracted from the values of non-heated enzyme fractions.

\section{Purification of PNB hydrolytic enzymes.}

A $B$. cinerea culture induced with 16-hha showed highest PNB hydrolytic activities at 6 days after induction. The culture was filtered and polysaccharides were removed by precipitation with 15 to $20 \%$ (v/v) acetone and centrifugation. From the supernatant acetone was removed by vacuum evaporation. The sample was subsequently concentrated to $30 \mathrm{ml}$ by ultrafiltration using an Amicon PM-10 membrane (cut off 10 $\mathrm{kDa}$ ), freeze-dried and resuspended in $2 \mathrm{ml}$ of elution buffer (50 mM Tris- $\mathrm{HCl}, \mathrm{pH} 7.5,100 \mathrm{mM} \mathrm{NaCl}$ ). After centrifugation $(5 \mathrm{~min}$ at $13,000 \times g)$, the supernatant was applied to a Sephadex G-50 column $(2.6 \times 100 \mathrm{~cm})$, equilibrated with elution buffer and the column was eluted at a flow rate of 10 $\mathrm{ml} / \mathrm{h}$. Fractions of $5 \mathrm{ml}$ were collected during $48 \mathrm{~h}$ and the even-numbered fractions were monitored for PNB hydrolytic activity. Fractions of each peak were pooled, dialyzed against $25 \mathrm{mM}$ imidazole-HCl, pH 7.4, and applied to a PBE 94 column (Pharmacia, $1.2 \times 35 \mathrm{~cm}$ ) equilibrated with $25 \mathrm{mM}$ imidazole- $\mathrm{HCl}, \mathrm{pH}$ 7.4. Elution with 1:8 diluted Polybuffer 74$\mathrm{HCl}, \mathrm{pH} 4.0$, at $30 \mathrm{ml} / \mathrm{h}$ during $12 \mathrm{~h}$ resulted in a $\mathrm{pH}$ gradient from 7.0 to 4.5 . Fractions of $5 \mathrm{ml}$ were collected and $\mathrm{pH}$ and PNB hydrolytic activity were determined in the even fractions. Fractions containing high activity were dialyzed (cut off 12 to $14 \mathrm{kDa}$ ) against distilled water to remove the Polybuffer and analyzed by polyacrylamide gel electrophoresis under denaturing conditions (SDS-PAGE). Electrophoresis was performed according to Laemmli (1970) with a $2 \%$ (w/v) stacking gel and a $15 \%(\mathrm{w} / \mathrm{v})$ running gel using the Mini-Protean II dual slab gel system (Bio-Rad). Molecular mass markers ranging from 14.2 to $66 \mathrm{kDa}$ (Sigma) were co-electrophoresed to estimate molecular masses of the various proteins. Proteins were stained with Coomassie Brilliant Blue R250.

\section{Enzyme assay for cutinase activity.}

Tomato cutin was coupled with the chromogenic group Remazol Brilliant Blue R (Wolf and Wirth 1990) by G. A. Wolf (Institut für Pflanzenpathologie und Pflanzenschutz der Georg-August-Universität, Göttingen, Germany). After coupling, colorless cutin became dark blue. Optimal $\mathrm{pH}$, temperature and concentration of Triton X-100 for the enzyme assay were determined using partially purified cutinase fractions. Cutin-RBB hydrolysis was optimal in $100 \mathrm{mM}$ sodiumphosphate buffer $\mathrm{pH} 5.6,0.5 \%$ (v/v) Triton X-100 supplemented with $1 \mathrm{mg}$ of insoluble cutin-RBB in a reaction volume of $100 \mu \mathrm{l}$. This suspension was incubated at $30^{\circ} \mathrm{C}$ under continuous gentle shaking for $1 \mathrm{~h}$. The background was measured in a parallel assay using protein fractions that had been heated for $5 \mathrm{~min}$ at $100^{\circ} \mathrm{C}$. Cutin-RBB particles were pelleted by centrifugation in a microfuge and the absorption of the supernatant at $590 \mathrm{~nm}$ was measured.

\section{Determination of amino \\ acid sequences.}

Purified protein fractions were subjected to SDS-PAGE (Laemmli 1970) and blotted onto PVDF-membrane in $50 \mathrm{mM}$ Tris-borate, $0.1 \%$ SDS and $20 \%$ methanol according to Bauw et al. (1990). After blotting for $8 \mathrm{~h}$ at $35 \mathrm{~V}$, the membrane was washed three times for $10 \mathrm{~min}$ in $10 \mathrm{mM}$ boric acid, $\mathrm{pH} 8$, and $25 \mathrm{mM} \mathrm{NaCl}$. Protein bands were stained with Coomassie Brilliant Blue R250 and cut out. In situ tryptic digestions, separations of peptides and amino acid sequence determination were performed as described by Bauw et al. (1990).

\section{RT-PCR.}

Total RNA was isolated from mycelium of $B$. cinerea strain SAS56 harvested 3 days after induction with 16-hha, using the Extract-A-Plant RNA isolation kit (Clontech). Poly(A) ${ }^{+}$RNA was isolated using the Oligotex-dT mRNA kit (Qiagen) and used as template in first-strand cDNA synthesis employing an oligo(dT) primer and Superscript Reverse Transcriptase (RT) (GibcoBRL/Life Technologies) according to the manufacturer's instructions. For PCR $1 \mu$ of RT mix was combined with $250 \mathrm{ng}$ of each primer, $5 \mathrm{mM}$ dNTPs and 1.2 units Ultma Polymerase (Perkin Elmer). Buffer and $\mathrm{MgCl}_{2}$ were added according to the manufacturer's instructions. The amplification started with $5 \mathrm{~min} 95^{\circ} \mathrm{C}$ followed by 35 cycles of $1 \mathrm{~min}$ $95^{\circ} \mathrm{C}, 1 \mathrm{~min} 55^{\circ} \mathrm{C}, 1 \mathrm{~min} 72^{\circ} \mathrm{C}$ and a final $2 \mathrm{~min}$ at $72^{\circ} \mathrm{C}$ before cooling to $4^{\circ} \mathrm{C}$. Amplified products were analyzed on a $2 \%$ agarose gel in TAE buffer and cloned into pCR-script $\mathrm{SK}^{+}$ (Stratagene). DNA sequencing was performed on doublestranded DNA using the CircumVent Thermal Cycle Sequencing Kit (New England Biolabs).

\section{Screening of genomic library.}

A genomic library of $B$. cinerea strain SAS56 in lambda EMBL3 was kindly provided by M. Kusters-Van Someren (Section of Molecular Genetics of Industrial Micro-organisms, Wageningen Agricultural University). From the genomic library, $2 \times 10^{4}$ recombinant phages were plated. Replica filters (Hybond- $\mathrm{N}^{+}$, Amersham) were made and hybridized for $16 \mathrm{~h}$ at $65^{\circ} \mathrm{C}$ in modified Church buffer $(0.5 \mathrm{M}$ sodium phosphate buffer, $\mathrm{pH}$ 7.2, 7\% SDS; Church and Gilbert 1984) in the presence of a random-primed $\left[\alpha-{ }^{32} \mathrm{P}\right] \mathrm{dATP}$ labeled probe. Filters were washed in $0.5 \times \mathrm{SSC}$ and $0.5 \% \mathrm{SDS}$ at $65^{\circ} \mathrm{C}$ and exposed to Kodak X-OMAT AR film. Positive plaques were purified by a second round of hybridization. DNA from selected phages of the genomic library was isolated using Qiagen columns according to the manufacturer's instructions and analyzed by digestion with SalI. Hybridizing fragments detected by Southern blot analysis were cloned and used for further subcloning and sequence analysis. DNA sequence analysis was performed on double-stranded DNA using the Dyedeoxy Terminator Cycle Sequencing Kit (Applied Biosystems). Analyses of the sequence data and alignment to known sequences in GenEMBL and SWISS-PROT databases were performed using the Wisconsin Package, Version 8, Genetics Computer Group, Madison, WI. All DNA manipulations not described were performed according to Sambrook et al. (1989). 


\section{Southern blot analysis.}

Genomic DNA of $B$. cinerea strain SAS56 was isolated according to Drenth et al. (1993), digested with restriction enzymes, fractionated on $0.7 \%$ agarose/TAE gel and blotted according to the manufacturer's instuctions onto Hybond- $\mathrm{N}^{+}$membranes (Amersham). The blot was hybridized in modified Church buffer, as described above, at $65^{\circ} \mathrm{C}$ for $18 \mathrm{~h}$ in the presence of a random-primed $\left[\alpha-{ }^{32} \mathrm{P}\right] \mathrm{dATP}$ labeled probe. Blots were washed in $0.2 \times \mathrm{SSC}$ and $0.5 \% \mathrm{SDS}$ at $65^{\circ} \mathrm{C}$ and exposed to Kodak X-OMAT AR film.

\section{Analysis of gene expression in vitro.}

Total RNA was isolated from mycelial fractions using the Extract-A-plant RNA isolation kit (Clontech). Samples of 10 $\mu \mathrm{g}$ total RNA were denatured with formamide and formaldehyde and subjected to electrophoresis on a $1.0 \%$ agarose gel containing formaldehyde (Sambrook et al. 1989). After blotting to Hybond- $\mathrm{N}^{+}$membranes (Amersham), blots were hybridized as described for Southern blots.

\section{Analysis of gene expression in planta.}

Conidia of sporulating cultures of B. cinerea strain SAS56 were harvested and resuspended in Gamborg's B5 medium (Duchefa) supplemented with $10 \mathrm{mM}$ glucose and $8.5 \mathrm{mM}$ potassium phosphate, $\mathrm{pH} 5.0$, and sprayed at a density of $10^{6}$ conidia per $\mathrm{ml}$ onto detached tomato leaves (Lycopersicon esculentum, cv. Moneymaker). Compound leaves were incubated with their stem inserted in wet florist's foam oasis, in closed plastic boxes with a transparent lid to obtain a humidity of $100 \%$. Before closing the boxes, the inoculum was airdried. The boxes were placed at $18^{\circ} \mathrm{C}$ with a light-dark cycle of $16 \mathrm{~h}$ light and $8 \mathrm{~h}$ darkness. Leaves were harvested at 0,4 , $8,12,16,20,24,32,48,72$ and $120 \mathrm{~h}$ after inoculation. Isolation of total RNA from the leaves, electrophoresis under denaturing conditions, blotting, and hybridization were performed as described above.

\section{ACKNOWLEDGMENTS}

We thank G. Bauw (Laboratory for Genetics, University of Gent, Belgium) for protein micro-sequencing, J. Salinas (LMA, Wageningen, The Netherlands) for providing tomato cutin, G. A. Wolf (Institut für Pflanzenpathologie und Pflanzenschutz der Georg-August-Universität, Göttingen, Germany) for coupling RBB to cutin, M. Kusters-Van Someren (Section of Molecular Genetics of Industrial Micro-organisms, Wageningen Agricultural University) for providing the genomic library of B. cinerea strain SAS56, and T. van Kampen (Dept. Molecular Biology, Wageningen Agricultural University) for DNA sequencing. M. H. A. J. Joosten is acknowledged for helpful comments and discussion on protein purification and $\mathrm{E}$. Pérez Benito for advice on tomato inoculations.

\section{LITERATURE CITED}

Baker, C. J., and Bateman, D. F. 1978. Cutin degradation by plant pathogenic fungi. Phytopathology 69:1577-1584.

Bauw, G., Holm Rasmussen, H., Van den Bulcke, M., Van Damme, J., Puype, M., Gesser, B., Celis, J. E., and Vandekerckhove, J. 1990. Two-dimensional gel electrophoresis, protein electroblotting and microsequencing: A direct link between proteins and genes. Electrophoresis 11:528-536.

Church, G. M., and Gilbert, W. 1984. Genomic sequencing. Proc. Natl. Acad. Sci. USA 81:1991-1995.

Drenth, A., Goodwin, S. B., Fry, W. E., and Davidse, L. C. 1993. Genotypic diversity of Phytophthora infestans in The Netherlands revealed by DNA polymorphisms. Phytopathology 83:1087-1092.

Edlich, W., Lorenz, G., Lyr, H., Nega, E., and Pommer, E-H. 1989. New aspects on the infection mechanism of Botrytis cinerea Pers. Neth. J.
Plant Pathol. 95 Suppl. 1:53-62.

Ettinger, W. F., Thukral, S. K., and Kolattukudy, P. E. 1987. Structure of cutinase gene, cDNA, and the derived amino acid sequence from phytopathogenic fungi. Biochemistry 26:7883-7892.

Jarvis, W. R. 1977. Botryotinia and Botrytis Species-Taxonomy, Physiology and Pathogenicity-A guide to literature. Canada Department of Agriculture, Ottowa.

Jefferson, R. A., Kavanagh, T. A., and Bevan, M. W. 1987. GUSfusions: $\beta$-glucuronidase as a sensitive and versatile gene fusion marker in higher plants. EMBO J. 6:3901-3907.

Laemmli, U. K. 1970. Cleavage of structural proteins during the assembly of the head of bacteriophage T4. Nature 277:680-685.

Martin, J. T., and Juniper, B. E. 1970. The Cuticles of Plants. St. Martins, New York.

Martinez, C., De Geus, P., Lauwereys, M., Matthyssens, G., and Cambillau, C. 1992. Fusarium solani cutinase is a lipolytic enzyme with a catalytic serine accessible to solvent. Nature 356:615-618.

McKeen, W. E. 1974. Mode of penetration of epidermal cell walls of Vicia faba by Botrytis cinerea. Phytopathology 64:461-467.

Nelson, N. 1944. A photometric adaptation of the Somogyi method for the determination of glucose. J. Biol. Chem. 153: 375-380.

Purdy, R. E., and Kolattukudy, P. E. 1973. Depolymerization of a hydroxy fatty acid biopolymer, cutin, by an extracellular enzyme from Fusarium solani f. sp. pisi: Isolation and some properties of the enzyme. Arch. Biochem. Biophys. 159:61-69.

Purdy, R. E., and Kolattukudy, P. E. 1975. Hydrolysis of plant cuticle by plant pathogens. Purification, amino acid composition and molecular weight of two isozymes of cutinase and a non-specific esterase from Fusarium solani f. sp. pisi. Biochemistry 14:2824-2831.

Rijkenberg, F. H. J., De Leeuw, G. T. N., and Verhoeff, K. 1980. Light and electron microscopy studies on the infection of tomato fruits by Botrytis cinerea. Can. J. Bot. 58:1394-1404.

Sambrook, J., Fritsch, E. F., and Maniatis, T. 1989. Molecular Cloning: A Laboratory Manual. 2nd ed. Cold Spring Harbor Laboratory Press, Cold Spring Harbor, New York.

Salinas, J., Warnaar, F., and Verhoeff, K. 1986. Production of cutin hydrolyzing enzymes by Botrytis cinerea in vitro. J. Phytopathol. 116:299-307.

Salinas, J. 1992. Function of cutinolytic enzymes in the infection of gerbera flowers by Botrytis cinerea. Ph. D. Thesis, University of Utrecht, The Netherlands.

Shishiyama, J., Araki, F., and Akai, S. 1970. Studies on cutin-esterase II. Characteristics of cutin-esterase from Botrytis cinerea and its activity on tomato-cutin. Plant Cell Physiol. 11:937-945.

Soliday, C. L., Dickman, M. B., and Kolattukudy, P. E. 1989. Structure of the cutinase gene and detection of promoter activity in the 5'flanking region by fungal transformation. J. Bacteriol. 171:1942-1951.

Stone, P. J., Makoff, A. J., Parish, J. H., and Radford, A. 1993. Cloning and sequence analysis of the glucoamylase gene of Neurospora crassa. Curr. Genet. 24:205-211.

Sweigard, J. A., Chumley, F. G., and Valent, B. 1992. Cloning and analysis of CUT1, a cutinase gene from Magnaporthe grisea. Mol. Gen. Genet. 232:174-182.

Trail, F., and Köller, W. 1990. Diversity of cutinases from plant pathogenic fungi: Evidence for a relationship between enzyme properties and tissue specificity. Physiol. Mol. Plant Pathol. 36:495-508.

Van den Heuvel, J. 1981. Effect of inoculum composition on infection of French bean leaves by Botrytis cinerea. Neth. J. Plant Pathol. 87:55-64.

Van der Vlugt-Bergmans, C. J. B., Brandwagt, B. F., Van't Klooster, J. W., Wagemakers, C. A. M., and Van Kan, J. A. L. 1993. Genetic variation and segregation of DNA polymorphisms in Botrytis cinerea. Mycol. Res. 97:1193-1200.

Van Kan, J. A. L., Van't Klooster, J. W., Wagemakers, C. A. M., Dees, D. C. T., and Van der Vlugt-Bergmans, C. J. B. 1997. Cutinase A of Botrytis cinerea is expressed, but not essential during penetration of gerbera and tomato. Mol. Plant-Microbe Interact. 10:30-38.

Von Heijne, G. 1986. A new method for predicting signal sequence cleavage sites. Nucleic Acids Res. 14:4683-4690.

Wolf, G. A., and Wirth, S. J. 1990. Application of soluble chromogenic substrates for assays of polysaccharide endo-hydrolase activity. Pages 409-413 in: Methods in Phytobacteriology. Z. Klement, K. Rudolph, D. C. Sands, eds. Akademiai Kiado, Budapest.

Yao, C., and Köller, W. 1994. Diversity of cutinases from plant pathogenic fungi: cloning and characterization of a cutinase gene from $\mathrm{Al}$ ternaria brassicicola. Physiol. Mol. Plant Pathol. 44:81-92. 